Article

\title{
The Co-Movement and Asymmetry between Energy and Grain Prices: Evidence from the Crude Oil and Corn Markets
}

\author{
Zhan-Ming Chen, Liyuan Wang, Xiao-Bing Zhang * and Xinye Zheng \\ School of Applied Economics, Renmin University of China, Beijing 100872, China; \\ chenzhanming@ruc.edu.cn (Z.-M.C.); wangliyuan@ruc.edu.cn (L.W.); zhengxinye@ruc.edu.cn (X.Z.) \\ * Correspondence: xiaobing.zhang@ruc.edu.cn
}

Received: 27 February 2019; Accepted: 3 April 2019; Published: 9 April 2019

\begin{abstract}
This paper investigates the co-movement and asymmetric interactions between energy and grain prices, based on the evidence from the crude oil and corn markets, the most important energy and grain markets, respectively. Time series analysis indicates that there is a consistent trend between the crude oil price and corn price with a significant positive correlation coefficient 0.7471 during the sampling period, from January 2008 to February 2016. In addition, we find that there is a long-run equilibrium relationship between the two commodities' prices. Moreover, while linear Granger causality tests suggest that there is a two-way Granger causality relationship between the price changes in the two markets, non-linear Granger causality tests suggest that there is only a one-way causality relationship from corn to oil price. However, both linear and non-linear Granger causality tests indicate the asymmetry of causality relationship between the two markets (the price change in corn market can more significantly Granger cause the change in crude oil market). Further analysis suggests that the contribution of the corn market to price discovery in a large commodity market is larger than that of the crude oil market.
\end{abstract}

Keywords: crude oil market; corn market; asymmetry; price discovery

\section{Introduction}

In recent years, the energy policies around the world tend to become more environment-friendly and there is an increasing focus on renewable energy. In this respect, one of the most remarkable developments in the energy sector is the rapid development of biofuels. Biofuel policy has been in place in the United States (US) since the Energy Policy Act of 1978, which was conceived by the US Congress as a response to the OPEC-induced oil shock. In 1990, with the concerns about climate change and pollution, the US Congress conceived the Clean Air Act of 1990, requiring that the gasoline must contain a minimum percentage of oxygen. Ethanol and methyl tertiary-butyl ether (MTBE) are both additives into regular gasoline, and MTBE was more popular because it was cheaper and more available and easier to transport and distribute. However, after the hidden costs and health risks of MTBE were convinced, the US Congress passed the Energy Policy Act of 2005. The new renewable fuel standards established by the Energy Policy Act of 2005 make ethanol the only available gasoline additive and the new standard became applicable in May 2006, which consequently lead to the ethanol production boom in the United States.

Along with the booming of ethanol, there are more and more corns that are used for ethanol production in the United States. As shown in Figure 1, corns used for fuel ethanol account for more than $35 \%$ of the whole production of corn in the US since 2010, competing with the traditional uses of corns (including for food and livestock feed). Meanwhile, fuel ethanol production and consumption in 
the US also takes off and the fuel ethanol plays an increasingly important role in the transportation sector. The market share of the fuel ethanol consumption, which is calculated by dividing the volume of ethanol consumption by the sum of motor gasoline and ethanol consumption, has reached $9.51 \%$ by the year 2015.

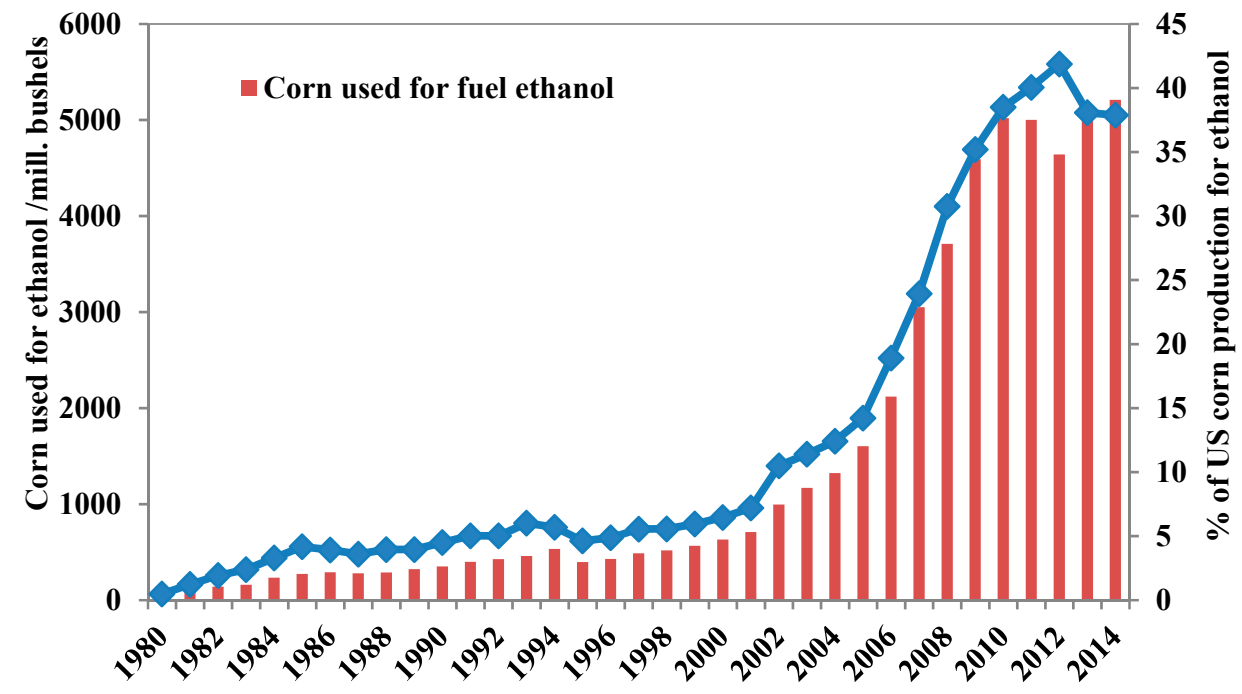

Source: USDA, US Bioenergy Statistics. (Notes: The data are collected in Marketing Year, e.g., '2014' means from September 2014 to August 2015).

Figure 1. Corn used for ethanol in the US.

Since the ethanol boom in the US in 2006, the interaction between the energy market and the agriculture market has become much stronger. Agriculture uses energy products directly in the form of gasoline, diesel and electricity as the fuel of the farm machinery. Meanwhile, the agriculture sector also uses energy-based input such as fertilizer and pesticides. Higher energy prices can make agricultural goods more expensive by raising the costs of production (including fuel, fertilizer, chemicals and other inputs) and transportation. Besides, crude oil and corn are naturally linked through the substitution possibility between gasoline and bio-ethanol. Higher oil prices would stimulate the growth of corn-based biofuels production and the expansion of the demand for corns, which can consequently boost the corn price.

Furthermore, along with the globalization, the gradual liberalization of financial markets, the rapid development of advanced communication technologies, and the financialization of commodity markets, different goods and assets have become more and more interlinked. For instance, crude oil and corn prices are both affected by the US dollar exchange rate, local military conflicts, monetary policy pursued by central banks and the increased demand for basic materials from rapidly growing emerging markets $[1,2]$.

Giving that there is a close link between the energy sector and the agricultural sector, it would be of great significance to investigate the long- and short-run dynamic relationship between the energy and agriculture commodity markets. Due to their different attributes, the energy and agricultural products may respond differently to the same economic, political or natural shocks. The extreme weather and climate events, and natural disasters, for instance, may have more significant effects on the agriculture commodity market. For example, the severe drought in 2002-2003 in Australia, one of the world's largest wheat producers, significantly cut down the global wheat production, thereby raising the wheat price dramatically, while the effect on the crude oil price is less significant.

Understanding the relationship between the energy and agriculture commodity markets will be useful for farmers, investors and even politicians. Commodity price shocks and varying degrees of fluctuations pose serious policy challenges to the decision-makers. Sharp movements in commodity prices have serious impacts in terms of trade, real income and fiscal position of countries that depend on 
these commodities. Therefore, a better understanding of the recent dynamics of energy and agriculture markets could assist decision-makers for a better macroeconomic policies and regulations of the commodity markets, which motivates this study.

In this paper, we use the crude oil market as the representation of the energy market, and the corn market as the representation of the agriculture market, due to the fact that corn is the most widely produced feed grain in the United States and is the most important feedstock in the extraction of the fuel ethanol. Meanwhile, corn is one of the most heavily-traded contracts in the agricultural commodity market. Focusing on the relationship between crude oil and corn markets, we investigate the longand short-term interaction between crude oil and corn prices and examine whether there is (linear and non-linear) Granger causality relationships between the two commodity markets. Moreover, we calculate the two markets' respective contribution to the price discovery of large commodity markets. Our results show that there is a long-run equilibrium relationship between the crude oil and corn markets. Moreover, while linear Granger causality tests suggest that there is a two-way Granger causality relationship between the returns in the two markets, non-linear Granger causality tests suggest that there is only unilateral causality running from the corn market to the crude oil market. Nevertheless, both linear and non-linear Granger causality tests indicate the asymmetry of the causality relationship between the two markets (the change in the corn market more significantly Granger causes the change in the crude oil market). Further analysis suggests that the contribution of the corn market to the price discovery in large commodity markets is larger than that of the crude oil market.

The reminder of the paper is organized as follows. Section 2 presents a review of the literature. Section 3 provides a description of the data. Then, we present the empirical methodologies in Section 4. Section 5 analyzes the empirical results of this study, including the long-term equilibrium and short-term adjustment between the crude oil and corn prices, the linear and non-linear Granger causality between the two markets, and their respective contribution to price discovery. Finally, Section 6 gives some concluding remarks.

\section{Literature Review}

There is an increasing number of studies on the agriculture commodity market due to the increasing concerns on agriculture supply security in the world, especially that in the developing world. A large literature on prices of agriculture commodities has mainly focused on analyzing the co-integration relationships between spot and futures prices and the basic conclusion is that, though a co-integration relationship does exist, futures prices generally dominate spot prices in agriculture commodity markets. For instance, Garbade and Silber [3] analyzed the price movements and price discovery in spot and futures markets for seven storable commodities, including corn, wheat, oats, orange, copper, gold and silver and they found that futures prices dominate spot price changes for most of these commodities. Yang et al. [4] investigated the price discovery function for storable agriculture commodities (corn, oats, soybeans, wheat, cotton and pork bellies) and non-storable agricultural commodities (hogs, live cattle, feeder cattle) and found that although, in general, storability does not affect the future price discovery function, future contracts can be used as a price discovery tool in all of these markets. Zapato et al. [5] investigated the co-integrating relationship between the New York futures prices and the Dominican Republic spot prices and found that the World Futures Sugar (WFS) price has a predictive power for the spot price of a small sugar-producing country. Mattos and Garica [6] examined the relationship between spot and futures prices in six agricultural markets of Brazil and found that the thinly traded future contracts have some degree of long-run co-integration relationship with the spot price but the highly-traded corn contracts show almost no interrelations between the future and spot prices.

While there is a large literature on world oil market focus on identifying the driving forces and determinant factors behind the volatility of oil price, such as economic crisis, oil supply and demand, OECD commercial inventory, OPEC behaviors, US dollar exchange rate, local military conflicts, natural hazards and speculative trading activities [7-10], or on the linkage between crude oil and other financial markets $[11,12]$, there is an increasing number of studies on the linkage and relationship between 
energy (mainly oil) and agriculture commodity markets. However, the results are mixed and there has been no consensus on the food-energy nexus. Some researchers indicate that the oil price has a significant effect on the agriculture commodity price. Trujillo-Barrera et al. [13] focused on the volatility spillovers in the US from energy to agricultural markets in the period 2006-2011. They discovered significant spillovers from oil to corn and ethanol markets, which seems to be particularly strong in high volatility periods for oil markets. They also identified significant volatility spillovers from corn to ethanol markets. Using co-integration and a linear Granger causality test Avalos [14] exploits a natural experiment arising from a significant change in 2006 on the nature of ethanol policies in the US to assess the relationship between oil, corn and soybean prices. He finds that there are substantial changes in the dynamic properties of corn and soybean prices and they are more closely related to oil prices, but the predictive causality seems to run from the crops to oil prices. In contrast, some research indicates that there is no direct relationship between oil and agricultural commodity prices. Zhang et al. [15], using monthly data from March 1989 through July 2008, found that there is no long-term relationship between oil and food (corn and soybeans) prices.

The studies on the mechanism of the linkage between oil and agricultural prices mainly focus on three key channels: (i) oil as a production cost in agriculture; (ii) biofuels; and (iii) co-movement of commodity prices with macroeconomic factors and financial indicators, according to Nazlioglu et al. [16], where they provide a comprehensive review on the studies based on each linkage. For instance, in terms of oil as an input for agriculture production, Baffes $[17,18]$ investigated the spillover effect of crude oil price changes on the prices of 35 internationally traded primary commodities and calculated the pass-through of crude oil price changes to the overall non-energy commodity index, the fertilizer index, agriculture and metals. They found that the highest pass-through of oil price changes is to the fertilizer index followed by agriculture. Considering biofuels as the channel for the linkage between oil and agriculture prices, the findings are mixed. Serra et al. [19] and Hassouneh et al. [20] examined the price linkages and transmission patterns in the US and Spain, respectively, and they both found long-run equilibrium relationships among the prices of biofuels and oil and strong links between energy and food prices. However, Zhang et al. [15] investigated both short- and long-run relationships between prices of fuel and agricultural commodities and found that there is no direct long-run price relationship between fuel and agricultural commodity prices and there is only limited, if any, direct short-run relationships. Recently, Sari et al. [21] investigated the roles of futures prices of crude oil, gasoline, ethanol, corn, soybeans and sugar in the energy-grain nexus, taking into account the ownand cross-market impacts for the lagged grain trading volume and the open interest in the energy and grain markets. They reveal that the conventional view, which states that the impacts run from oil to gasoline to ethanol to grains in the energy-grain nexus, does not hold well in the long-run because the oil price is influenced by gasoline, soybeans and soybean oil. Besides, in the short-run, there is a two-way feedback in both directions for all markets. The grain trading volume's effect across the oil and gasoline markets is more pronounced in the short-run than in the long-run. As for the third channel for the linkage between oil and agriculture prices, i.e., macroeconomic policies and financial indicators, Krichene [22] examined oil price movements between January 2000 and October 2007 and argued that the rapid increase observed in oil and other commodity prices can be attributed to the expansionary monetary policies during the early 2000s.

To sum up, it should be noted that the existing research related to energy and agriculture commodity prices has focused more on the co-movement of the two markets rather than the asymmetric interactions between the two markets or their asymmetric role in price discovery. Therefore, this study attempts to investigate both the co-movement and asymmetric interactions between energy and grain prices, based on the evidence from the crude oil and corn markets, which are the most important energy and grain markets, respectively. By employing the time-series econometric methods, this paper analyzes the co-integration and (linear and non-linear) causality relationship between the two markets and their respective contribution to price discovery. Some recent studies share similar interest with this paper. For instance, Nazlioglu [23] investigated the co-integration and (linear and non-linear) Granger 
causality relationship between the world oil and agricultural commodity prices (corn, soybean and wheat) by using the weekly data spanning from 1994 to 2010. Her linear causality test indicates that the oil prices and the agricultural commodity prices do not influence each other while the non-linear causality analysis shows that there is a persistent unidirectional non-linear causality running from the oil prices to the corn and to the soybean prices. Different from Nazlioglu [23], we used daily data from January 2008 to February 2016, given that high frequency data may capture the dynamic casual linkages between different commodity markets better. Our conclusions are very different from that of Nazlioglu [23]. Moreover, we also conducted the price discovery (Permanent-Transitory (PT) and Information Share (IS) models) analysis to further investigate the contribution of different markets in price discovery of large commodity markets, which is absent in the previous studies on the co-movement and transmission among energy and food commodity prices.

\section{The Data}

In this paper, we used daily time series spot price data for the crude oil and corn prices from 22 January 2008 to 29 February 2016 (this choice of the study period was restricted by our access to the daily corn price from the Chicago Mercantile Exchange). The crude oil price is the Brent crude oil spot price in US dollars per barrel from the US Energy Information Administration (EIA). The corn price is the US No.2 yellow maize (corn) price in US cents per bushel from the Chicago Mercantile Exchange. It can be seen in Figure 2 that the two markets do have some consistent trends in the sample period. The correlation coefficient between the crude oil price and the corn price is 0.7471 , indicating that they could have co-movement and share common information in their price dynamics. The descriptive description of the data is presented in Table 1.

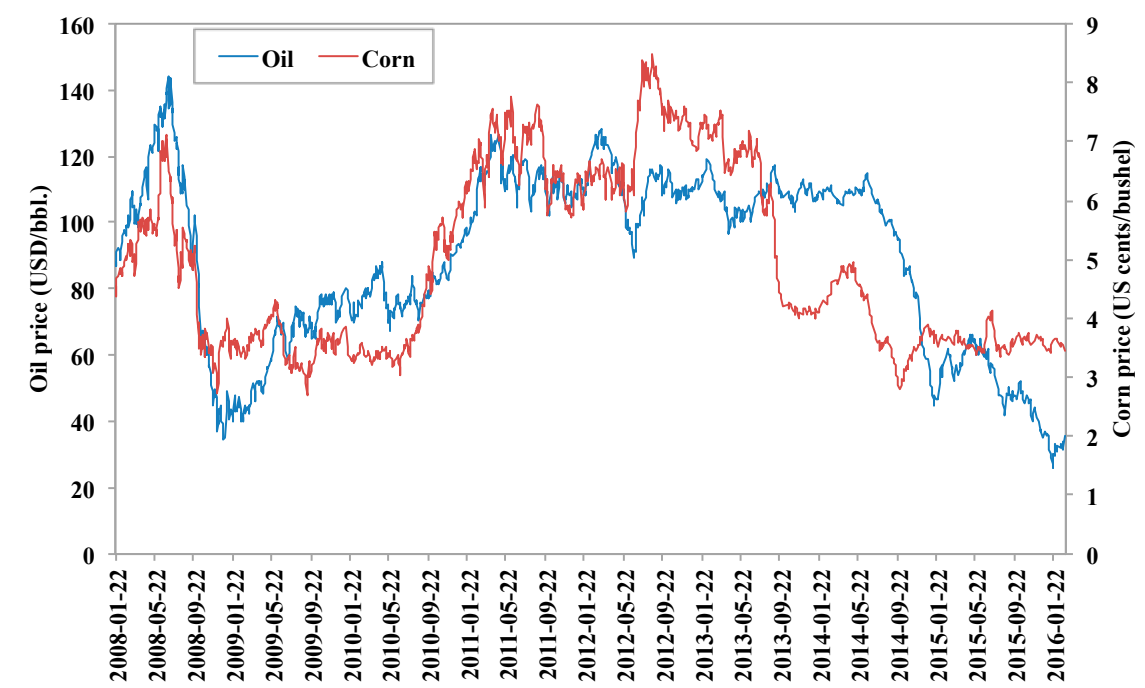

Source: The crude oil price is the Brent crude oil spot price in US dollars per barrel from US Energy Information Administration (EIA); the corn price is the US No.2 yellow maize (corn) price in US cents per bushel from the Chicago Mercantile Exchange.

Figure 2. Daily crude oil spot price and the corn spot price.

Table 1. Descriptive Statistics.

\begin{tabular}{cccccc}
\hline Variable & Obs & Mean & Std. Dev. & Min & Max \\
\hline Crude oil price $\mathrm{P}^{\mathrm{o}}$ & 1831 & 89.495 & 26.004 & 26.01 & 143.95 \\
Corn price $\mathrm{P}^{\mathrm{c}}$ & 1831 & 4.972 & 1.528 & 2.695 & 8.49 \\
Ln $\left(\mathrm{P}^{\mathrm{O}}\right)$ & 1831 & 4.443 & 0.339 & 3.258 & 4.969 \\
Ln $\left(\mathrm{P}^{\mathrm{c}}\right)$ & 1831 & 1.557 & 0.304 & 0.991 & 2.139 \\
First-order diff. Ln $\left(\mathrm{P}^{\mathrm{O}}\right)$ & 1830 & -0.000490 & 0.024 & -0.168 & 0.181 \\
First-order diff. Ln $\left(\mathrm{P}^{\mathrm{C}}\right)$ & 1830 & -0.000148 & 0.022 & -0.121 & 0.109 \\
\hline
\end{tabular}


Figures 3 and 4 show the returns of the crude oil price and the corn price, respectively. Returns are calculated as the first differences of the logarithms of the prices. During the periods of 2008-2009 and 2015-2016, the crude oil market has more dramatic volatility than the other periods in the sampling period. As for the corn market, the fluctuation of return is higher in the first half of the sampling period.

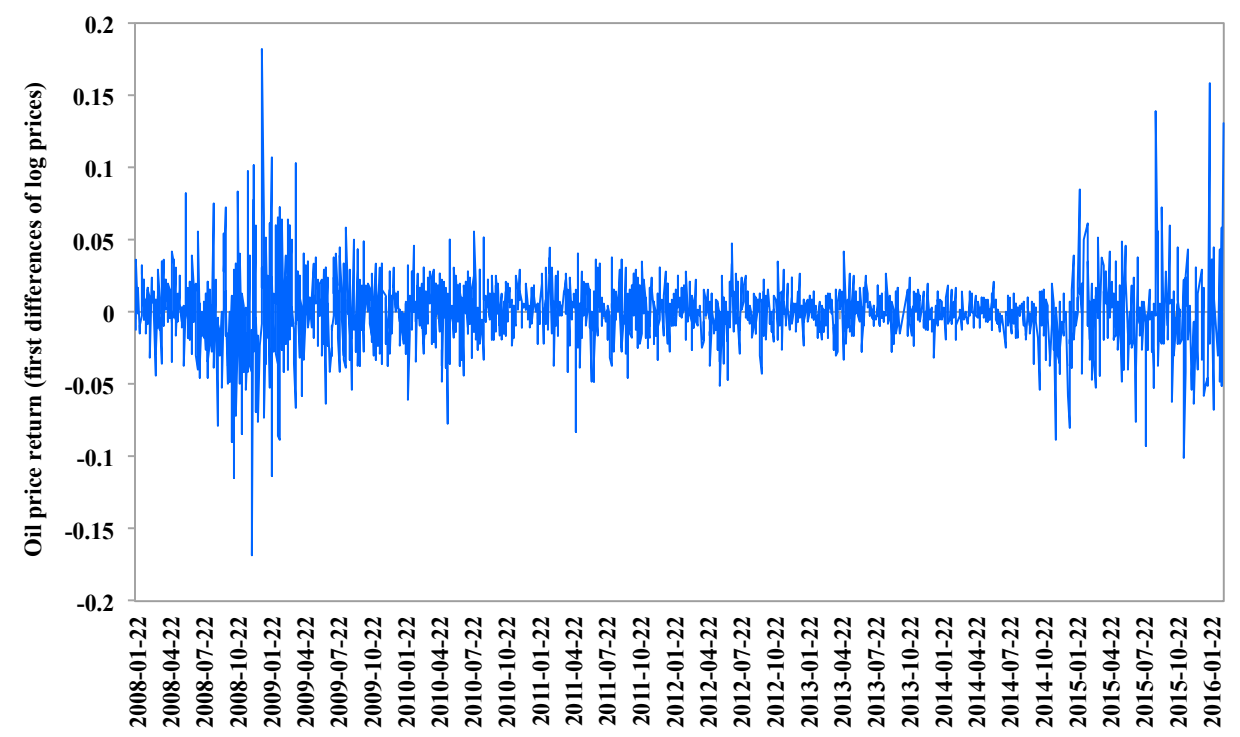

Figure 3. Returns of the crude oil price (the first differences of the logarithm of the prices).

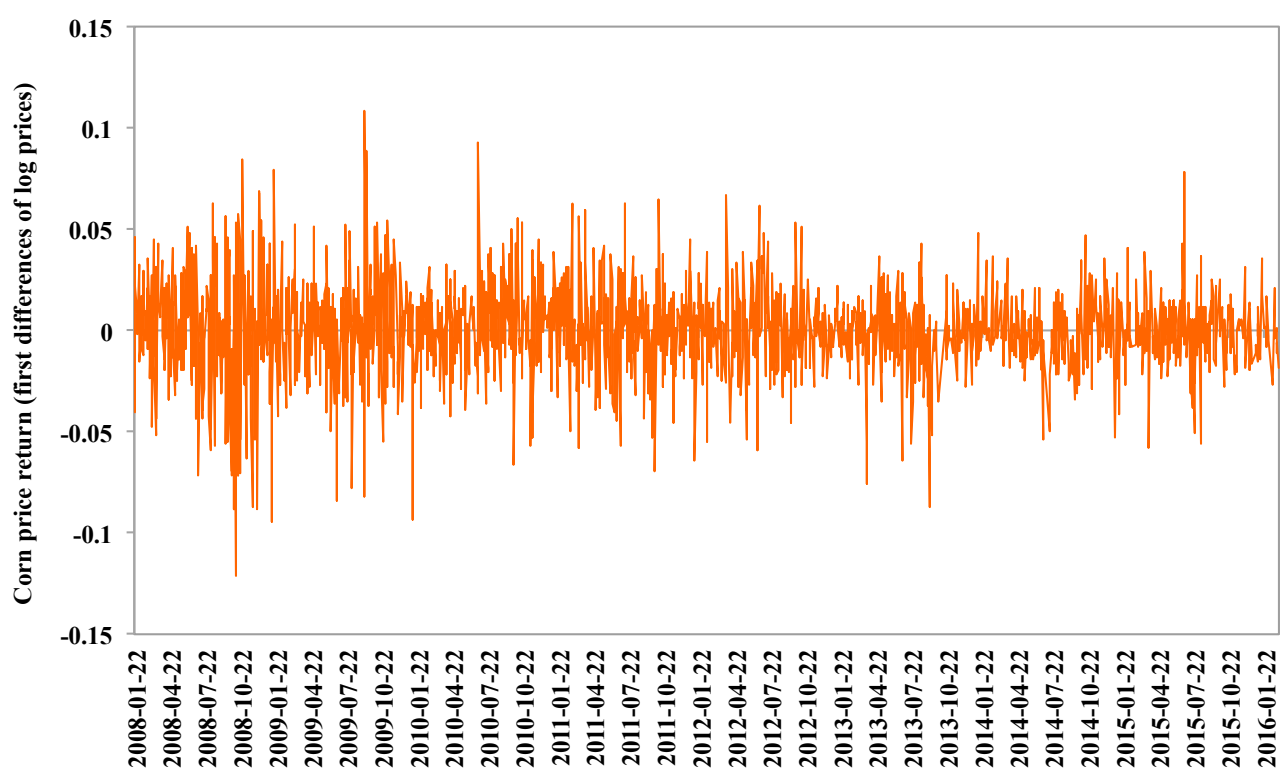

Figure 4. Returns of the corn price (the first differences of the logarithm of the prices).

We used the ADF (augmented Dickey-Fuller) test to check the stationarity of the logarithm of the prices and the returns, as displayed in Table 2. The results of the ADF test show that the logarithm of the two commodities' prices are not stationary, but the first order difference of the (log) prices is stationary, which implies that both price series are I(1), i.e., the returns of the oil and corn prices are stationary. Therefore, we used the logarithm of the prices in the Vector Error Correction (VEC) Model. In addition, the Vector Auto-Regression (VAR) Model was estimated in terms of the returns (the first differences of the logarithm of the oil and corn prices) to avoid spurious regression and inferences. 
Table 2. T statistic values of ADF test for the crude oil price and the gold price.

\begin{tabular}{ccc}
\hline & \multicolumn{1}{c}{$\boldsymbol{\operatorname { l n } P _ { t } ^ { o }}$} & $\ln \boldsymbol{P}_{t}^{c}$ \\
\hline Level $(\log )$ price & $-0.530(0.9822)$ & $-1.388(0.8643)$ \\
First-order diff. (log) prices & $-41.467(0.0000)$ & $-42.570(0.0000)$. \\
\hline
\end{tabular}

Note: $p$-values are reported in parentheses.

\section{Methodology}

Given the importance of testing whether there exists a lead-and-lag price mechanism between the two commodities for the whole large commodity market forecast, in this section, we first present the methods to detect whether there is a co-integration relationship between the crude oil and corn markets, and then we test both the linear and non-linear Granger causality between the returns of crude oil and corn. Finally, we use the Permanent-Transitory (PT) model and Information Share (IS) model to find out the contribution of the crude oil price and the corn price to the common effective price of the co-integration system.

\subsection{Co-Integration Test between the Crude Oil and Corn Markets}

Non-stationary variables may obey a common long-run relationship, which means that there is a stationary linear combination of these variables. If the linear combination does exist, we may say that there is a co-integration relationship between these variables. To test whether there is a long-run equilibrium relationship between the two commodities, we use the two-step procedure provided by Engle and Granger [24]. The long-run equilibrium equations are:

$$
\begin{aligned}
& \operatorname{Ln} P_{t}^{o}=\phi_{1}+\theta_{1} \operatorname{Ln} P_{t}^{c}+z_{1 t}, \\
& \operatorname{Ln} P_{t}^{c}=\phi_{2}+\theta_{2} \operatorname{Ln} P_{t}^{o}+z_{2 t},
\end{aligned}
$$

where $P_{t}^{o}$ is the price of the crude oil, $P_{t}^{c}$ is the price of the corn, and $z_{1 t}$ and $z_{2 t}$ are residuals, respectively. If the stationarity test indicates that the residuals are stationary, a long-run equilibrium may exist between the crude oil price and corn price.

\subsection{Granger Causality Test}

\subsubsection{Linear Granger Causality Test}

We use the stationary price returns of the commodities (logarithmic difference of original price series) to detect the lead and lag relationship between the oil and the corn prices. Specifically, we establish the VAR model:

$$
\begin{aligned}
& \mathrm{r}_{\mathrm{t}}^{\mathrm{o}}=\pi_{10}+\sum_{\mathrm{i}=1}^{\mathrm{p}} \varphi_{1 \mathrm{i}} \mathrm{r}_{\mathrm{t}-\mathrm{i}}^{\mathrm{o}}+\sum_{j=1}^{\mathrm{p}} \phi_{1 \mathrm{j}} \mathrm{r}_{\mathrm{t}-\mathrm{j}}^{\mathrm{c}}+\varepsilon_{1 \mathrm{t}}, \\
& \mathrm{r}_{\mathrm{t}}^{\mathrm{c}}=\pi_{20}+\sum_{\mathrm{i}=1}^{\mathrm{p}} \varphi_{2 \mathrm{i}} \mathrm{r}_{\mathrm{t}-\mathrm{i}}^{\mathrm{c}}+\sum_{\mathrm{j}=1}^{\mathrm{p}} \phi_{2 \mathrm{j}} \mathrm{r}_{\mathrm{t}-\mathrm{j}}^{\mathrm{o}}+\varepsilon_{2 \mathrm{t}},
\end{aligned}
$$

where $\mathrm{r}_{\mathrm{t}}^{\mathrm{o}}=\operatorname{Ln} P_{t}^{o}-\operatorname{Ln} P_{t-1}^{o}$ denotes the price returns of the crude oil, $\mathrm{r}_{\mathrm{t}}^{\mathrm{c}}=\operatorname{Ln} P_{t}^{c}-\operatorname{Ln} P_{t-1}^{c}$ denotes the price returns of the corn, and $\mathrm{p}$ is the lag length of the equation, which is chosen according to the Akaike Information Criterion (AIC) and should ensure that there is no autocorrelation in the $\varepsilon_{1 \mathrm{t}}$ and $\varepsilon_{2 \mathrm{t}}$. For the first equation, we will test the null hypothesis: $\phi_{11}=\phi_{12}=\cdots=\phi_{1 \mathrm{p}}=0$, if the null hypothesis is rejected, the change in the corn price return linearly Granger causes the change in the crude oil price return. Similarly, we test $\phi_{21}=\phi_{22}=\cdots=\phi_{2 p}=0$ to investigate whether the oil price return is the linear Granger causality of the corn price return. 


\subsubsection{Non-Linear Granger Causality Test}

Previous studies show that financial time series usually have remarkable non-linear dynamics. However, the traditional linear Granger test can fail to identify the non-linear relationship between variables, which implies significant bias can appear when employing the linear Granger method to test the Granger causality between the variables that may potentially have a non-linear relationship. Baek and Brock [25], and Hiemstra and Jones [26] proposed a method to conduct the non-linear Granger causality test, which has been widely applied in the empirical studies in the economics and finance fields. However, Diks and Panchenko [27] showed that the non-linear Granger causality test proposed by Hiemstra and Jones [26] has the issue of over-rejection and therefore developed a non-parametric $T_{n}$ test to investigate whether there is non-linear Granger causality between variables. This non-parametric test method has the advantage that it will consider the possible variations in conditional distribution based on the chosen bandwidth so as to overcome the over-rejection problem in the H-J test, thereby making the results of the test more robust and reliable. Therefore, we used the non-parametric $T_{n}$ test proposed by Diks and Panchenko [27] to investigate whether there are the non-linear Granger causality relations between oil and corn prices. The basic idea of $T_{n}$ test is as follows:

Let $\{X\}$ and $\{Y\}$ denote the residuals obtained from the two equations in the VAR model (2), respectively. Suppose that $X_{t}^{L x}=\left(X_{t-L_{x}+1}, \cdots \cdots, X_{t}\right)$ and $Y_{t}^{L y}=\left(Y_{t-L_{y}+1}, \cdots \cdots, Y_{t}\right)$, where $L x, L y>0$, are the delay vectors. Let us examine the null hypothesis that the past observations of $X_{t}^{L x}$ do not contain any additional information about $Y_{t+1}$ (beyond that in $Y_{t}^{L y}$ ), i.e.,

$$
H_{0}: Y_{t+1}\left|\left(X_{t}^{L x} ; Y_{t}^{L y}\right) \sim Y_{t+1}\right| Y_{t}^{L y}
$$

The null hypothesis implies that the $(L x+L y+1)$-dimensional vector $W_{t}=\left(X_{t}^{L x}, Y_{t}^{L y}, Z_{t}\right),($ where $\left.Z_{t}=Y_{t+1}\right)$ has invariant distribution. If we ignore the time notation and let $L x=L y=1$, the null hypothesis implies that the distribution of $Z$ given that $(X, Y)=(x, y)$ is the same as that of $Z$ given $Y=y$, which implies that $H_{0}$ can be restructured using the joint probability density function:

$$
\frac{f_{X, Y, Z}(x, y, z)}{f_{Y}(y)}=\frac{f_{X, Y}(x, y)}{f_{Y}(y)} \cdot \frac{f_{X, Z}(y, z)}{f_{Y}(y)} .
$$

In other words, Equation (4) states that $X$ and $Z$ are independent, when $Y=y$ for each fixed value of $y$. Diks and Panchenko [27] show that the restated null hypothesis implies:

$$
q \equiv E\left[f_{X, Y, Z}(X, Y, Z) f_{Y}(Y)-f_{X, Y}(X, Y) f_{Y, Z}(Y, Z)\right]=0 .
$$

Let $\hat{f}_{W}\left(W_{i}\right)$ denote a local density estimator of a $d_{W}$-variate random vector $W$ at $W_{i}$, i.e., $\hat{f}_{W}\left(W_{i}\right)=$ $\left(2 \varepsilon_{n}\right)^{-d_{w}}(n-1)^{-1} \sum_{j, j \neq i} I_{i j}^{W}$, where $I_{i j}^{W}=I\left(\left\|W_{i}-W_{j}\right\|<\varepsilon_{n}\right)$ and $I(\cdot)$ is the indicator function and $\varepsilon_{n}$ is the bandwidth, which depends on the sample size $n$. Then, the non-parametric test statistic $T_{n}$ can be constructed as Equation (6), which can be used to conduct the non-linear Granger causality test between variables:

$$
T_{n}\left(\varepsilon_{n}\right)=\frac{n-1}{n(n-2)} \sum_{i}\left(\hat{f}_{X, Z, Y}\left(X_{i}, Z_{i}, Y_{i}\right) \hat{f}_{Y}\left(Y_{i}\right)-\hat{f}_{X, Y}\left(X_{i}, Y_{i}\right) \hat{f}_{Y, Z}\left(Y_{i}, Z_{i}\right)\right)
$$

For $L x=L y=1$ and if $\varepsilon_{n}=C n^{-\beta}\left(C>0, \frac{1}{4}<\beta<\frac{1}{3}\right)$, Diks and Panchenko [27] prove that the test statistic in Equation (6) satisfies:

$$
\sqrt{n} \frac{\left(T_{n}\left(\varepsilon_{n}\right)-q\right)}{S_{n}} \stackrel{D}{\rightarrow} N(0,1),
$$

where $\stackrel{D}{\rightarrow}$ denotes convergence in distribution and $S_{n}$ is an estimator of the asymptotic variance of $T_{n}(\cdot)[27]$. 


\subsection{PT and IS Model for Price Discovery}

Based on the results of the VEC model, we adapt two popular common factor models to investigate the mechanisms of price discovery: The first model is the Permanent-Transitory (PT) model by Gonzalo and Granger [28]; the second model is the Information Shares (IS) model by Hasbrouck [29]. We first used the PT model to estimate the common long-memory components of the co-integration system between the crude oil price and the corn price and the two markets' contribution to the common factor, which is a function of the coefficients of the error-correction model. Then, the IS model is employed to measure the two markets' information share, which is defined as the proportional contribution of that market's innovation to the innovation in the common efficient price.

\subsubsection{Permanent-Transitory (PT) Model}

As proved by Stock and Watson [30], if two time series are co-integrated, in other words, $z_{t}=y_{t}-A x_{t}$ is stationary, there must exist a common factor $f_{t}$.

$$
\left[\begin{array}{c}
y_{t} \\
x_{t}
\end{array}\right]=\left[\begin{array}{c}
A \\
1
\end{array}\right] f_{t}+\left[\begin{array}{c}
\widetilde{y}_{t} \\
\widetilde{x}_{t}
\end{array}\right]
$$

where $y_{t}$ and $x_{t}$ are $\mathrm{I}(1), \widetilde{y}_{t}$ and $\widetilde{x}_{t}$ are $\mathrm{I}(0), f_{t}$ is the common effective price, and might be the unobserved factor and the driving force resulting in the co-integration relationship. Each time series $Y_{t}$ can be decomposed into two components, $Y_{t}=f_{t}+\widetilde{Y}_{t}$, one is the permanent component $f_{t}$, and the other is the transitory component $\widetilde{Y}_{t}$, which can be called the noisy price of the market. The two components convey different kinds of information.

There are several reasons why we are interested in $f_{t}$. Firstly, if the model of the complete set of variables is too complex, and if we are only interested in the long-run behavior, we can use a small set of common long-run effective factors. Secondly, the estimation of the common factor allows us to decompose a variable into two components that convey different kinds of information, the permanent component (trend component) $f_{t}$ and the transitory components (cyclical component) $\tilde{Y}_{t}$. Finally, singling out the common factors allows us to investigate the relationship between the common factor and other variables.

Based on the Vector Error Correction Model (VECM):

$$
\begin{aligned}
& \Delta \operatorname{Ln} P_{t}^{o}=\alpha_{1}\left(\operatorname{Ln} P_{t-1}^{o}+\beta \operatorname{Ln} P_{t-1}^{c}\right)+\sum_{i=1}^{q} \gamma_{1 i} \Delta \operatorname{Ln} P_{t-i}^{o}+\sum_{i=1}^{q} \theta_{1 i} \Delta \operatorname{Ln} P_{t-i}^{c}+\varepsilon_{1 t}, \\
& \Delta \operatorname{Ln} P_{t}^{c}=\alpha_{2}\left(\operatorname{Ln} P_{t-1}^{o}+\beta \operatorname{Ln} P_{t-1}^{c}\right)+\sum_{i=1}^{q} \gamma_{2 i} \Delta \operatorname{Ln} P_{t-i}^{o}+\sum_{i=1}^{q} \theta_{2 i} \Delta \operatorname{Ln} P_{t-i}^{c}+\varepsilon_{2 t},
\end{aligned}
$$

where $\alpha_{1}$ and $\alpha_{2}$ are the error-correction coefficients. $\beta$ denotes the cointegrating coefficient. $\varepsilon_{1 t}$ and $\varepsilon_{2 t}$ are serially uncorrelated innovations with zero mean.

In the equation $Y_{t}=f_{t}+\widetilde{Y}_{t}$, where $Y_{t}=\left(\operatorname{Ln} P_{t}^{o}, \operatorname{Ln} P_{t}^{c}\right)^{\prime}$, and $f_{t}=\Gamma Y_{t}, \Gamma=\left(\gamma_{1}, \gamma_{2}\right), f_{t}$ can be regarded as a weighted average of the prices of the two markets. In addition, $\Gamma=\left(\gamma_{1}, \gamma_{2}\right)$ is the coefficient vector of common factor, which can be considered as the weights of crude oil price and corn price in the portfolio, and $\gamma_{1}+\gamma_{2}=1$. Besides, as shown by Gozalo and Granger [28], $\Gamma$ is orthogonal to the error-correction coefficient $\left(\alpha_{1}, \alpha_{2}\right)^{\prime}$, in other words, $\alpha_{1} \gamma_{1}+\alpha_{2} \gamma_{2}=0$. Therefore, along with the condition $\gamma_{1}+\gamma_{2}=1, \gamma_{1}$ and $\gamma_{2}$ can be solved out from the two equations above.

\subsubsection{Information Shares (IS) Model}

According to Hasbrouck [29], a market's contribution to price discovery is its information share, which is defined as the proportion of the efficient price innovation variance that can be attributed to that market. Price variables can be expressed as the vector moving average (VMA) form:

$$
\Delta P_{t}=\Psi(L) e_{t}
$$


where $e_{t}$ is a zero-mean vector of serially uncorrelated disturbances with covariance matrix $\Omega$,

$$
\Omega=\left[\begin{array}{cc}
\sigma_{1}^{2} & \rho \sigma_{1} \sigma_{2} \\
\rho \sigma_{1} \sigma_{2} & \sigma_{2}^{2}
\end{array}\right]
$$

where $\sigma_{1}^{2}$ and $\sigma_{2}^{2}$ are the variance of $\varepsilon_{1 t}$ and $\varepsilon_{2 t}$, respectively; and $\rho$ is the correlation coefficient between $\varepsilon_{1 t}$ and $\varepsilon_{2 t} . \Psi$ is a polynomial in the lag operator. If the prices are cointegrated of order n-1, then all the rows of $\Psi(1)$ are identical, and $\Psi(1) e_{t}$ constitutes the long-run impact of a disturbance on each of the price. Letting $\psi$ denote the common row vector, the price levels can be written as:

$$
P_{t}=P_{0}+\iota \psi\left(\sum_{s=1}^{t} e_{s}\right)+\Psi^{*}(L) e_{t}
$$

where $\iota=(1,1)^{\prime}$. Additionally, $\Psi^{*}(L)$ is a matrix polynomial in the lag operator. The second term $\iota \psi\left(\sum_{s=1}^{t} e_{s}\right)$ is the random-walk component that is common to all prices. The variance of the common factor is $\operatorname{Var}\left(\psi e_{t}\right)=\psi \Omega \psi^{\prime}$. The information share of a market is the proportion of value $\operatorname{Var}\left(\psi e_{t}\right)$ that is attributable to that market. If the covariance matrix $\Omega$ is diagonal, the information shares of the crude oil market and the corn market are:

$$
\begin{aligned}
& S_{o}=\frac{\psi_{1}^{2} \sigma_{1}^{2}}{\psi \Omega \psi^{\prime}}, \\
& S_{c}=\frac{\psi_{2}^{2} \sigma_{2}^{2}}{\psi \Omega \psi^{\prime}} .
\end{aligned}
$$

Baillie et al. [31] investigated the relationship between the PT model and the IS model, and they discovered that $\frac{\psi_{1}}{\psi_{2}}=\frac{\gamma_{1}}{\gamma_{2}}$. Therefore, the information shares are:

$$
\begin{aligned}
& S_{o}=\frac{\gamma_{1}^{2} \sigma_{1}^{2}}{\gamma_{1}^{2} \sigma_{1}^{2}+\gamma_{2}^{2} \sigma_{2}^{2}}, \\
& S_{c}=\frac{\gamma_{2}^{2} \sigma_{2}^{2}}{\gamma_{1}^{2} \sigma_{1}^{2}+\gamma_{2}^{2} \sigma_{2}^{2}} .
\end{aligned}
$$

However, if the covariance matrix is not diagonal, one can use Cholesky factorization to minimize the correlation, where $\Omega=M M^{\prime}$,

$$
\mathbf{M}=\left[\begin{array}{cc}
m_{11} & 0 \\
m_{12} & m_{22}
\end{array}\right]=\left[\begin{array}{cc}
\sigma_{1} & 0 \\
\rho \sigma_{2} & \sigma_{2}\left(1-\rho^{2}\right)^{1 / 2}
\end{array}\right] .
$$

Therefore, the information shares can be written as:

$$
\begin{aligned}
& S_{0}=\frac{\left(\gamma_{1} m_{11}+\gamma_{2} m_{21}\right)^{2}}{\left(\gamma_{1} m_{11}+\gamma_{2} m_{21}\right)^{2}+\left(\gamma_{2} m_{22}\right)^{2}}, \\
& S_{c}=\frac{\left(\gamma_{2} m_{22}\right)^{2}}{\left(\gamma_{1} m_{11}+\gamma_{2} m_{21}\right)^{2}+\left(\gamma_{2} m_{22}\right)^{2}},
\end{aligned}
$$

and $S_{o}+S_{c}=1$.

The factorization imposes a greater share on the first price, unless $m_{12}=0$, therefore, we need to change the order of variables in the factorization procedure to get an upper and a lower limit of 
the information share of a market price. The average of the lower bound and upper bound can be regarded as a reasonable estimation of a market's contribution to price discovery [11,31].

\section{Empirical Results}

In this section, empirical results are reported and discussed in three parts. The first part reports the results from the VEC model, discussing the long-run equilibrium and the short-run adjustment of the two markets. The next part is the lead and lag relationship between the two markets, i.e., the Granger causality relationship between the crude oil and corn prices. The last part reports the two markets' contribution to price discovery from the PT model and the IS model.

\subsection{The Long-Run Equilibrium and the Short-Run Adjustment between the Crude Oil Market and the Corn Market}

According to the results of the unit root test in Section 3 (see Table 2), we confirm that the Ln (crude oil price) and the Ln (corn price) are both I(1). Then, we have to identify whether there is a co-integration relationship between the crude oil price and the corn price. The results of the unit root test of the error term from Equation (1) are displayed in Table 3.

Table 3. Estimation results of integration Equation (1) and the ADF test results of the residuals.

\begin{tabular}{ccccc}
\hline $\begin{array}{c}\text { Dependent } \\
\text { Variables }\end{array}$ & $\boldsymbol{\phi}$ & $\boldsymbol{\theta}$ & F-Statistic & $\begin{array}{c}\boldsymbol{T} \text { Statistic of ADF } \\
\text { Test for } \boldsymbol{z}\end{array}$ \\
\hline $\operatorname{Ln} P_{t}^{o}$ & $3.1901(0.0000)$ & $0.8043(0.0000)$ & $1974.48(0.0000)$ & $-1.699(0.0893)$ \\
$L n P_{t}^{o}$ & $-1.3100(0.0000)$ & $0.6454(0.0000)$ & $1974.48(0.0000)$ & $-2.303(0.0213)$ \\
\hline
\end{tabular}

The results show that both equations are jointly significant at the $1 \%$ level and that residuals are stationary (at the 10\% level and 5\% level, respectively). Therefore, we know that there is a long-run equilibrium relationship between the crude oil price and the corn price, which is likely due to the common economic factors (e.g., the US dollar index) that affect the two markets and the possible substitution of biofuel from coal and oil in some sectors (e.g., transport sector) of the world economy. This result is consistent with a number of previous studies (see e.g., Harri et al. [32] where they identified a long run equilibrium relationship between oil prices and all agricultural prices except wheat).

Based on the long-run equilibrium between the crude oil market and the corn market, we can introduce a Vector Error Correction Model (VECM) to study the short-run adjustment between the two markets. The estimation results of the VECM equations are presented in Table 4, where the optimal maximum lag is determined by the principle of minimum AIC value.

Table 4. Estimation results of the Vector Error Correction Model (VECM) equations.

\begin{tabular}{ccc}
\hline & Dependent Variable: $\Delta \operatorname{Ln} \mathbf{P}_{\mathbf{t}}^{\mathbf{o}}$ & Dependent Variable: $\Delta \operatorname{Ln} \mathbf{P}_{\mathbf{t}}^{\mathbf{c}}$ \\
\hline $\operatorname{ecm}(-1)$ & $-0.004428^{* * *}$ & 0.000767 \\
& $(-2.75)$ & $(0.51)$ \\
$\Delta \mathrm{LnP}$ & 0.006250 & $-0.041922 *$ \\
& $(0.26)$ & $(-1.86)$ \\
$\Delta \mathrm{LnP} \mathrm{P}_{\mathrm{t}-1}^{\mathrm{c}}$ & $0.067460^{* * *}$ & 0.016345 \\
& $(2.61)$ & $(0.68)$ \\
Constant & -0.000038 & -0.000222 \\
$\chi^{2}$ & $(-0.07)$ & $(0.41)$ \\
$R^{2}$ & $17.2294^{* * *}$ & 3.8113 \\
& 0.0094 & 0.0021 \\
\hline
\end{tabular}

(T statistic in parentheses, ${ }^{* * *} p<0.01,{ }^{*} p<0.1$ ).

The estimations of $\alpha_{1}$ and $\alpha_{2}$ are -0.004428 and 0.000767 , respectively. The estimation of $\alpha_{1}$ is significant at the $1 \%$ level in the $\Delta \mathrm{LnP}_{\mathrm{t}}^{\mathrm{o}}$ equation, while the estimation of the $\alpha_{2}$ is insignificant in the $\Delta \mathrm{LnP}_{\mathrm{t}}^{\mathrm{c}}$ equation. This result indicates that the long-term equilibrium between the crude oil market and 
the corn market may significantly adjust the short-term price change of the two markets so that they do not deviate from the long-term equilibrium path very far. Specifically, the adjustment to the short-term price change of the crude oil is significant, while the adjustment to the short-term corn price change is not significant. That is, when there is a deviation from the long-run relationship between the corn and oil price, it seems that it is the crude oil price that will be adjusted to preserve the long-run relationship.

Besides, regarding the interactions between the two markets in terms of their price change, the results show that the change of the corn price has a strongly positive effect on the change of crude oil price, while the effect of the change of the oil price on the change of the corn price is found to be less significant. While many studies in the literature report neutrality or a weak effect of agricultural prices to oil price changes (see, e.g., Zhang et al. [15]; Zhang and Reed [33]), the positive effect of the change in agricultural price on crude oil price has also been found in previous studies (see, e.g., Nazlioglu and Soytas [34]). This might be related to the portfolio diversification strategies of global investors/speculators and the increasing investment in agricultural commodities, which leads to a higher integration between energy-finance and agricultural markets (Nazlioglu and Soytas [34]).

\subsection{The Lead-And-Lag Relationship between the Crude Oil and Corn Market}

We have shown that there is a long-run equilibrium relationship between the crude oil and corn market. Now let us further investigate the spillover effect between the two markets and examine the price or return lead-and-lag relationship between the two markets through Granger causality test. Since it requires the concerned time series to be stationary, we use the first differences of the logarithm of the prices (i.e., the return), which were proven to be stationary in Section 3.

\subsubsection{The Linear Granger Causal Relationship}

According to the principle of minimum AIC value, we chose the optimal lag order for the VAR model like Equation (1) to be 1, which implies that the VAR model is actually specified as follows:

$$
\begin{aligned}
& r_{t}^{o}=\beta_{10}+\beta_{11} r_{t-1}^{o}+\gamma_{11} r_{t-1}^{c}+\varepsilon_{1 t}, \\
& r_{t}^{c}=\beta_{20}+\beta_{21} r_{t-1}^{c}+\gamma_{21} r_{t-1}^{o}+\varepsilon_{2 t} .
\end{aligned}
$$

The estimation results of the VAR model are shown in Table 5. It can be seen that the return of corn has a significantly positive effect on the return of crude oil, while the return of crude oil has a negative effect on the return of corn.

Table 5. Estimation results of the Vector Auto-Regression (VAR) model.

\begin{tabular}{ccc}
\hline & Dependent Variable: $\mathbf{r}_{\mathbf{t}}^{\mathbf{o}}$ & Dependent Variable: $\mathbf{r}_{\mathbf{t}}^{\mathbf{c}}$ \\
\hline $\mathrm{r}_{\mathbf{t}-1}^{\mathrm{o}}$ & 0.00649 & $-0.04196^{*}$ \\
& $(0.27)$ & $(-1.86)$ \\
$\mathrm{r}_{\mathrm{t}-1}^{\mathrm{c}}$ & $0.07280^{* * *}$ & 0.01542 \\
& $(2.82)$ & $(0.64)$ \\
Constant & -0.00047 & -0.00015 \\
$R^{2}$ & $(-0.85)$ & $(-0.28)$ \\
No. of observations & 0.0048 & 0.0019 \\
\multicolumn{2}{c}{ (T statistic in parentheses, $\left.{ }^{* * *} p<0.01 *^{*} p<0.1\right)$}
\end{tabular}

In a VAR model, each random disturbance influences all the endogenous variables. In addition, random disturbances may exhibit their influence in some of the endogenous variables earlier and others later. The Granger causality test can check a VAR for this type of temporal ordering, in other words, the lead-and-lag relationship between the two markets. The results of the linear Granger causality test are reported in Table 6 . It can be seen that the change in the corn price return does Granger cause the return of the crude oil at the 1\% level. Additionally, the change in the crude oil 
price return also Granger causes the change in the corn price return at the $10 \%$ level. This implies that the Granger causality relationship between the two markets is asymmetric: the price change in corn market can more significantly Granger cause the change in the crude oil market. While many studies in the literature find a bidirectional spillover effect between crude oil and agricultural commodity markets through similar Granger causality tests (see, e.g., Nazlioglu and Soytas [34]), there are studies which found only unidirectional volatility spillovers from corn to crude oil after the 2008-09 financial crisis (see, e.g., Lu et al [35]). Our findings somehow lie between these two branches of literature.

Table 6. Results of the linear Granger causality test.

\begin{tabular}{ccc}
\hline Null Hypothesis & W Statistic & $p$-Value \\
\hline$r_{t}^{c} \nRightarrow r_{t}^{o}$ & 7.9674 & 0.005 \\
$r_{t}^{o} \nRightarrow r_{t}^{c}$ & 3.4581 & 0.063 \\
\hline
\end{tabular}

Note: $\nRightarrow$ denotes that there is no linear Granger causality from the left market to the right market.

\subsubsection{The Non-Linear Granger Causal Relationship}

As mentioned above, the traditional linear Granger causality test can fail to identify the non-linear relationship between variables, which is actually common in the economics and finance fields (Zhang and Wei [11]). Therefore, here we conduct the non-linear Granger causality test based on the method proposed by Diks and Panchenko [27], as described in Section 4.2.2. Following previous studies [15], we present the results of the non-linear Granger test for different maximum lags $(L x=L y=1,2, \cdots \cdots, 8)$, as shown in Table 7.

Table 7. Results of the non-linear Granger causality test.

\begin{tabular}{|c|c|c|c|}
\hline Null Hypothesis & $L x=L y$ & $T_{n}$ Statistic & $p$-Value \\
\hline$Y \nRightarrow X$ & \multirow{2}{*}{1} & 2.403 & 0.0081 \\
\hline$X \nRightarrow Y$ & & 0.423 & 0.3363 \\
\hline$Y \nRightarrow X$ & \multirow{2}{*}{2} & 2.356 & 0.0092 \\
\hline$X \nRightarrow Y$ & & 0.600 & 0.2743 \\
\hline$Y \nRightarrow X$ & \multirow{2}{*}{3} & 2.948 & 0.0016 \\
\hline$X \nRightarrow Y$ & & 1.338 & 0.0905 \\
\hline$Y \nRightarrow X$ & \multirow{2}{*}{4} & 2.932 & 0.0017 \\
\hline$X \nRightarrow Y$ & & 1.470 & 0.0707 \\
\hline$Y \nRightarrow X$ & \multirow[b]{2}{*}{5} & 2.834 & 0.0023 \\
\hline$X \nRightarrow Y$ & & 0.950 & 0.1711 \\
\hline$Y \nRightarrow X$ & \multirow{2}{*}{6} & 2.661 & 0.0039 \\
\hline$X \nRightarrow Y$ & & 0.574 & 0.2830 \\
\hline$Y \nRightarrow X$ & \multirow{2}{*}{7} & 2.494 & 0.0063 \\
\hline$X \nRightarrow Y$ & & 0.503 & 0.3076 \\
\hline$Y \nRightarrow X$ & \multirow{2}{*}{8} & 2.184 & 0.0145 \\
\hline$X \nRightarrow Y$ & & 0.257 & 0.3985 \\
\hline
\end{tabular}

Note: $Y$ denotes residual series when the corn price return acts as the dependent variable in the VAR model and $X$ denotes the residual series when the crude oil price return acts as the dependent variable in the VAR model; $\nRightarrow$ denotes that there is no non-linear Granger causality from the left market to the right market.

It can be seen that the non-linear Granger test results generally support the Granger causality relationship from the corn market to the crude oil market, while do not support the hypothesis of Granger causality from the crude oil market to the corn market. This reinforces our previous conclusion based on the linear Granger causality test that the Granger causality relationship between the two markets is asymmetric and that the price change in corn market can more significantly Granger cause the change in the crude oil market.

The finding that in the short run, impulses seem to flow from crop prices to oil prices, is consistent with Avalos [14], where he employed co-integration and a linear Granger causality test to assess the 
relationship between oil, corn and soybean prices, through exploiting a natural experiment arising from a significant change in the US biofuel policy in 2006. He found that the predictive causality seems to run from the crop prices to oil prices, in reverse of the expected direction. Our results from the non-linear Granger causality test reinforce the causality direction from crop prices to oil prices.

\subsection{Analysis of the Two Markets' Contribution to Price Discovery}

As two of most important large commodity markets, their price movement can reflect the price trends of the whole large commodity market. By investigating their respective contribution to price discovery, it would be helpful for forecasting the price trend of the whole large commodity market.

\subsubsection{Permanent-Transitory (PT) Model}

As mentioned above, Stock and Watson [30] think the price vector can be divided into two components, $\operatorname{Ln} P_{t}=f_{t}+\widetilde{Y}_{t}$, where $f_{t}$ denotes the common effective price in the two markets and $\widetilde{Y}_{t}$ is the transitory component. In our case, $f_{t}=\gamma_{1} \operatorname{Ln} P_{t}^{o}+\gamma_{2} \operatorname{Ln} P_{t}^{c}$, where two equations $\gamma_{1}+\gamma_{2}=1$ and $\alpha_{1} \gamma_{1}+\alpha_{2} \gamma_{2}=1$ hold. According to the estimation of the vector error correction coefficient (see Table 4), $\hat{\alpha}_{1}=-0.004428$ and $\hat{\alpha}_{2}=0.000767$. Then $\gamma_{1}$ and $\gamma_{2}$ can be solved from the two equations: $\gamma_{1}=0.1476, \gamma_{2}=0.8524$, which means that the contribution of the crude oil market is $14.76 \%$, and the contribution of the corn market is $85.24 \%$, i.e., the contribution of the corn market is much larger than the crude oil price. The common effective price $f_{t}=\gamma_{1} L n P_{t}^{o}+\gamma_{2} \operatorname{Ln} P_{t}^{c}$ can then be obtained, as shown in Figure 5.

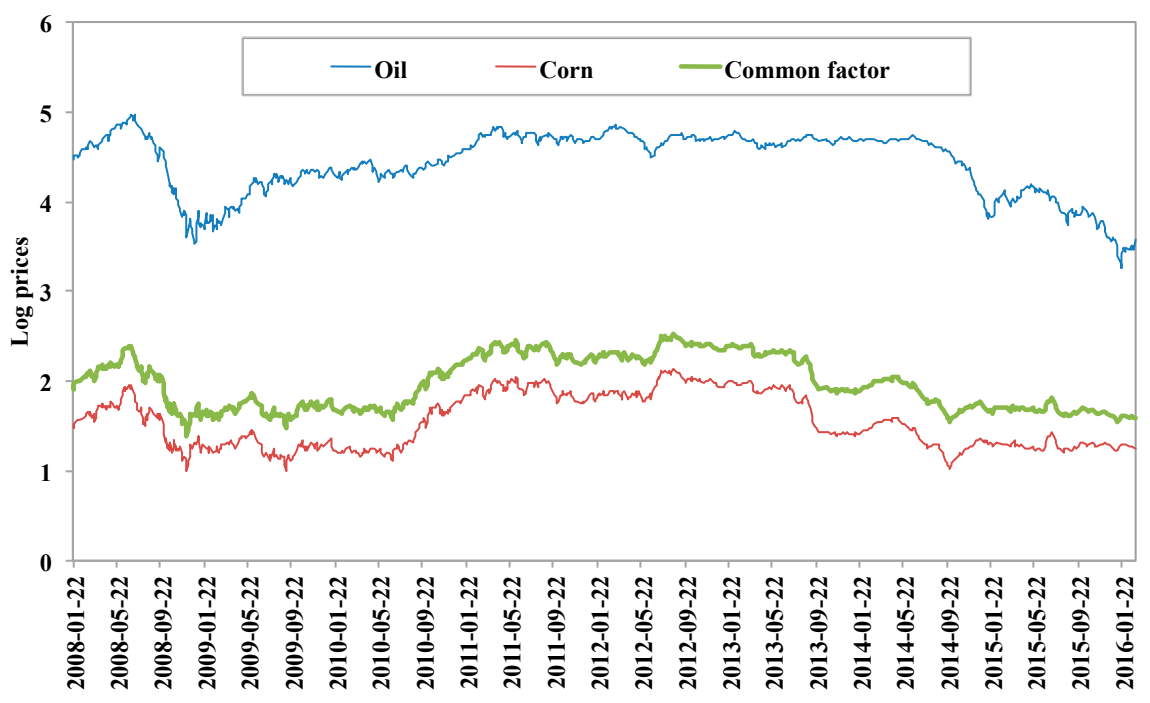

Figure 5. The crude oil price, corn price and their common effective price

\subsubsection{Information Shares (IS) Model}

Based on the results of the PT model, we constructed an IS model and calculated the information shares of the two markets. With the estimation of $\rho=0.2350, \sigma_{1}=0.02375$, and $\sigma_{2}=0.02218$, one can then calculate the information shares with two different orders of variables (whether crude oil price or corn price works as the first variable, see details in Section 4) as follows:

Case 1 (when oil price works as the first variable):

$$
\mathbf{M}=\left[\begin{array}{cc}
m_{11} & 0 \\
m_{21} & m_{22}
\end{array}\right]=\left[\begin{array}{cc}
\sigma_{1} & 0 \\
\rho \sigma_{2} & \sigma_{2}\left(1-\rho^{2}\right)^{1 / 2}
\end{array}\right] .
$$




$$
m_{11}=\sigma_{1}=0.02375, m_{21}=\rho \sigma_{2}=0.0052123, \text { and } m_{22}=\sigma_{2}\left(1-\rho^{2}\right)^{1 / 2}=0.02156 \text {, which implies }
$$
that information shares of the markets are:

$$
\begin{aligned}
& S_{o}=\frac{\left(\gamma_{1} m_{11}+\gamma_{2} m_{21}\right)^{2}}{\left(\gamma_{1} m_{11}+\gamma_{2} m_{21}\right)^{2}+\left(\gamma_{2} m_{22}\right)^{2}}=0.1576, \\
& S_{c}=\frac{\left(\gamma_{2} m_{22}\right)^{2}}{\left(\gamma_{1} m_{11}+\gamma_{2} m_{21}\right)^{2}+\left(\gamma_{2} m_{22}\right)^{2}}=0.8424 .
\end{aligned}
$$

Case 2 (when corn price works as the first variable):

$$
\begin{aligned}
\mathrm{M} & =\left[\begin{array}{cc}
m_{11} & 0 \\
m_{21} & m_{22}
\end{array}\right]=\left[\begin{array}{cc}
\sigma_{2} & 0 \\
\rho \sigma_{1} & \sigma_{1}\left(1-\rho^{2}\right)^{1 / 2}
\end{array}\right] . \\
m_{11}=\sigma_{2}=0.02218, m_{21} & =\rho \sigma_{1}=0.005581, m_{22}=\sigma_{2}\left(1-\rho^{2}\right)^{1 / 2}=0.02156, \text { which implies: } \\
S_{c} & =\frac{\left(\gamma_{2} m_{11}+\gamma_{1} m_{21}\right)^{2}}{\left(\gamma_{2} m_{11}+\gamma_{1} m_{21}\right)^{2}+\left(\gamma_{1} m_{22}\right)^{2}}=0.9711 \\
S_{o} & =\frac{\left(\gamma_{1} m_{22}\right)^{2}}{\left(\gamma_{2} m_{11}+\gamma_{1} m_{21}\right)^{2}+\left(\gamma_{1} m_{22}\right)^{2}}=0.0289 .
\end{aligned}
$$

Following Ballie et al. [31] and Zhang and Wei [11], we take average of results in the above two (orders of variables) cases to get a reasonable estimate of contributions to price discovery.

$$
\begin{aligned}
& \bar{S}_{o}=0.0932, \\
& \bar{S}_{c}=0.9068 .
\end{aligned}
$$

From the results, it can be noted that the PT model and IS model have similar results. Both models suggest that the contribution of the corn market to the price discovery of the large commodity markets is larger than that of the crude oil market $(85.24 \%$ versus $14.76 \%$ in the PT model; $90.68 \%$ versus $9.32 \%$ in the IS model), which implies that among the price trends of the large commodity market, the role of corn outweighs that of the crude oil. This indicates that as one of the most heavily traded contracts in the agricultural commodity market, corn has gained an important market position and wide acknowledgement of investors.

\section{Conclusions}

This paper investigates both the co-movement and asymmetric trends between energy and grain prices, based on the evidence from the crude oil market and corn market, which are two of most important representatives for large commodity markets. Using time-series econometric methods, we analyzed the co-integration and (linear and non-linear) causality relationship between the two markets and their respective contribution to price discovery based on daily data sampling from January 2008 to February 2016.

We find that there is a consistent trend between the crude oil price and corn price with a significant positive correlation coefficient 0.7471 during the sampling period. Additionally, co-integration analysis suggests that there is a long-run equilibrium relationship between the two commodities' prices, which is likely due to the common economic factors (e.g., the US dollar index) that affect the two markets and the possible substitution of biofuel from coal and oil in some sectors (e.g., transport sector) of the world economy. 
Moreover, while linear Granger causality tests suggest that there is a two-way Granger causality relationship between the two markets, non-linear Granger causality tests suggest that there is only unilateral Granger causality running from the corn market to the oil market. However, both linear and non-linear Granger causality tests indicate the asymmetry of the causality relationship between the two markets. Specifically, the change in the corn market can more significantly Granger cause the change in the crude oil market. Interestingly, our results are very different from those in Nazlioglu [23], where she finds that the linear causality test suggests that the oil prices and the agricultural commodity prices do not influence each other but the non-linear causality analysis shows that there is a persistent unidirectional non-linear causality running from the oil prices to the corn and to the soybeans prices. Actually, our results suggest that when we analyze the main factors driving the short-term price change of crude oil, the volatility of the corn market is necessary to be considered as an important factor and can provide a supplementary reference.

Furthermore, price discovery analysis based on both the PT model and IS model suggests that the contribution of the corn market to the price discovery in large commodity markets is larger than that of crude oil market $(85.24 \%$ versus $14.76 \%$ in the PT model and $90.68 \%$ versus $9.32 \%$ in the IS model), which implies that it would be helpful and important to take the main grain markets such as the corn market into account when predicting the price trend of the whole large commodity market.

This study is not without limitations. For instance, we ignored a number of factors that might affect the price dynamics of the energy and grain markets (e.g., demand shocks, climate negotiation events, and so on). A direction for further research would be to identify the common factors that have influence on both energy and grain markets and the factors that only affect one of the markets, and to investigate how the co-movement and asymmetry of the energy and grain markets can be affected by various economic, political and natural shocks (identified through structural break test) to provide a more complete story regarding the price dynamics in the two markets. For instance, further analysis with more variables incorporated, including nature disaster, OPEC behaviors, global demand change, monetary policy and financialization of commodity prices and so on, would be a valuable area to explore.

Author Contributions: All authors collectively conceived the research and carried out the analysis. L.W. and X.-B.Z. led the analysis and paper writing with contributions and guidance from Z.-M.C. and X.Z.

Funding: This research was funded by the National Natural Science Foundation of China (No. 71603267) and the Natural Science Foundation of Beijing (No. 9192012).

Acknowledgments: The authors would like to thank the two anonymous referees for their helpful comments and suggestions on the preliminary draft of this paper, according to which the content was improved. The authors also would like to thank the participants at the 2017 Annual Conference on Energy Economics and Management at Renmin University of China for their helpful discussions and comments on this paper. All errors and omissions remain the sole responsibility of the authors.

Conflicts of Interest: The authors declare no conflict of interest.

\section{References}

1. Gilbert, C.L. How to Understand High Food Prices. J. Agric. Econ. 2010, 61, 398-425.

2. Coleman, L. Explaining crude oil prices using fundamental measures. Energy Policy 2012, 40, 318-324. [CrossRef]

3. Garbade, K.; Silber, W.L. Price movements and price discovery in futures and cash markets. Rev. Econ. Stat. 1983, 64, 289-297. [CrossRef]

4. Yang, J.; Bessler, D.A.; Leathan, D. Asset storability and price discovery in commodity futures market: A new look. J. Futures Mark. 2001, 21, 279-300. [CrossRef]

5. Zapato, H.O.; Fortenberry, T.R.; Armstrong, D. Price discovery in the futures and cash market for sugar. Paper Presented at the Southern Agricultural Economics Association Annual Meeting, Mobile, AL, USA, 1-5 February 2003. 
6. Mattos, F.; Garica, P. Price discovery in thinly traded markets: Cash and futures relationships in Brazilian agricultural futures markets. In Proceedings of the NCCC-134 Conference on Applied Commodity Price Analysis, Forecasting and Market Risk Management, Saint Lois, MO, USA, 19-20 April 2004.

7. Zhang, Y.J.; Fan, Y.; Tsai, H.T.; Wei, Y.M. Spillover effect of US dollar exchange rate on oil prices. J. Policy Model. 2008, 30, 973-991.

8. Kaufmann, R.K.; Ullman, B. Oil prices, speculation, and fundamentals: Interpreting causal relations among spot and futures prices. Energy Econ. 2009, 31, 550-558.

9. Zhang, Y.J. Speculative trading and WTI crude oil futures price movement: An empirical analysis. Appl. Energy 2013, 107, 394-402. [CrossRef]

10. Zhang, Y.J.; Wang, Z.Y. Investigating the price discovery and risk transfer functions in the crude oil and gasoline futures markets: Some empirical evidence. Appl. Energy 2013, 104, 220-228. [CrossRef]

11. Zhang, Y.J.; Wei, Y.M. The crude oil market and the gold market: Evidence for cointegration, causality and price discovery. Resour. Policy 2010, 35, 168-177. [CrossRef]

12. Zhang, Y.J.; Wei, Y.M. The dynamic influence of advanced stock market risk on international crude oil return: An empirical analysis. Quant. Financ. 2011, 11, 967-978. [CrossRef]

13. Trujillo-Barrera, A.; Mallory, M.; Garcia, P. Volatility spillovers in US crude oil, ethanol, and corn futures Markets. J. Agric. Resour. Econ. 2012, 37, 247-262.

14. Avalos, F. Do oil prices drive food prices? The tale of a structural break. J. Int. Money Financ. 2014, 42, 253-271. [CrossRef]

15. Zhang, Z.; Lohr, L.; Escalante, C.; Wetzstein, M. Food versus fuel: What do prices tell us? Energy Policy 2010, 38, 445-451. [CrossRef]

16. Nazlioglu, S.; Erdem, C.; Soytas, U. Volatility spillover between oil and agricultural commodity markets. Energy Econ. 2013, 36, 658-665. [CrossRef]

17. Baffes, J. Oil spills on other commodities. Resour. Policy 2007, 32, 126-134. [CrossRef]

18. Baffes, J. More on the energy/nonenergy price link. Appl. Econ. Lett. 2010, 17, 1555-1558. [CrossRef]

19. Serra, T. Volatility spillovers between food and energy markets: A semiparametric approach. Energy Econ. 2011, 33, 1155-1164. [CrossRef]

20. Hassouneh, I.; Serra, T.; Goodwin, B.K.; Gil, J.M. Non-parametric and parametric modeling of biodiesel, sunflower oil, and crude oil price relationships. Energy Econ. 2012, 34, 1507-1513. [CrossRef]

21. Sari, R.; Hammoudeh, S.; Chang, C.L.; McAleer, M. Causality between market liquidity and depth for energy and grains. Energy Econ. 2012, 34, 1683-1692. [CrossRef]

22. Krichene, N. Crude Oil Prices: Trends and Forecast. Working Paper 08/133; International Monetary Fund: Washington, DC, USA, 2008.

23. Nazlioglu, S. World oil and agricultural commodity prices: Evidence from nonlinear causality. Energy Policy 2011, 39, 2935-2943. [CrossRef]

24. Engle, R.F.; Granger, C.W.J. Co-integration and Error Correction: Representation, Estimation, and Testing. Econometrica 1987, 55, 251-276. [CrossRef]

25. Baek, K.G.; Brock, W.A. A Nonparametric Test for Independence of a Multivariate Time Series. Work. Pap. 1992, 2, 137-156.

26. Hiemstra, C.; Jones, J.D. Testing for Linear and Nonlinear Granger Causality in the Stock Price-Volume Relation. J. Financ. 1994, 49, 1639-1664.

27. Diks, C.G.H.; Panchenko, V. A new statistic and practical guidelines for nonparametric Grangercausality testing. J. Econ. Dyn. Control 2006, 30, 1647-1669. [CrossRef]

28. Gonzalo, J.; Granger, C. Estimation of common long-memory components in cointegrated systems. J. Bus. Econ. Stat. 1995, 13, 27-35.

29. Hasbrouck, J. One Security, Many Markets: Determining the Contributions to Price Discovery. J. Financ. 1995, 50, 1175-1199. [CrossRef]

30. Stock, J.H.; Watson, M.W. Testing for Common Trends. J. Am. Stat. Assoc. 1988, 83, 1097-1107. [CrossRef]

31. Baillie, R.T.; Booth, G.G.; Tse, Y.; Zabotina, T. Price discovery and common factor models. J. Financ. Mark. 2002, 5, 309-321. [CrossRef]

32. Harri, A.; Nalley, L.; Hudson, D. The relationship between oil, exchange rates, and commodity prices. J. Agric. Appl. Econ. 2009, 41, 501-510. [CrossRef] 
33. Zhang, Q.; Reed, M. Examining the impact of the world crude oil price on China's agricultural commodity prices: The case of corn, soybean, and pork. In Proceedings of the Southern Agricultural Economics Association Annual Meetings, Dallas, TX, USA, 2-5 February 2008.

34. Nazlioglu, S.; Soytas, U. Oil price, agricultural commodity prices, and the dollar: A panel cointegration and causality analysis. Energy Econ. 2012, 34, 1098-1104. [CrossRef]

35. Lu, Y.; Yang, L.; Liu, L. Volatility Spillovers between Crude Oil and Agricultural Commodity Markets since the Financial Crisis. Sustainability 2019, 11, 396. [CrossRef]

(C) 2019 by the authors. Licensee MDPI, Basel, Switzerland. This article is an open access article distributed under the terms and conditions of the Creative Commons Attribution (CC BY) license (http://creativecommons.org/licenses/by/4.0/). 